\title{
The effect of a boron oxide layer on hydrogen production by boron hydrolysis
}

\author{
Tareq Abu Hamed ${ }^{1,2 *}$, Bara Wahbeh ${ }^{3}$, Roni Kasher ${ }^{3}$ \\ ${ }^{1}$ The Dead Sea and Arava Science Center, Tamar Regional Council, Israel \\ ${ }^{2}$ Arava Institute for Environmental Studies, Hevel Eilot, Israel \\ 3, Ben-Gurion University of the Negev, Sde-Boqer, Israel \\ *Corresponding author. Tel: +97286356694, Fax: +97286356634, E-mail: tareq@arava.org
}

\begin{abstract}
Hydrolysis of boron is investigated as a part of a boron/boron oxide solar, water-splitting, thermochemical cycle. Boron was hydrolysed and boron oxide was gasified with steam in a tubular reactor. The influence of the reactor temperature and time on hydrogen conversion was measured at furnace set point temperatures of 873,973 and $1073 \mathrm{~K}$. The hydrogen production rate was measured by inline gas chromatography. The products were analyzed by X-ray diffraction. The average hydrogen production efficiency of $92 \%$ was obtained for both 973 and $1073 \mathrm{~K}$. The formation of a boric acid layer on the reactor walls was attributed to the gasification of the boron oxide. The X-ray analysis shows $100 \%$ conversion of the boron to boron oxide and boric acid.
\end{abstract}

Keywords: hydrogen, thermochemical cycle, boron, oxide layer removal

\section{Introduction}

Hydrogen is an abundant and clean fuel with high energy density, making it a leading candidate in the search for an alternative to fossil fuels. However, the storage and transportation of hydrogen fuel for practical applications (e.g. internal combustion engine or fuel cells) remain among the most difficult problems to overcome before hydrogen can serve as a real alternative to fossil fuels [1]. Numerous methods for storage of hydrogen on-board vehicles have been considered, including compressed gas, liquid hydrogen and hydride compounds. Each method has significant and unresolved technical, safety and economic issues. Finding a feasible, on-board hydrogen storage solution is one of the major challenges in achieving a hydrogen economy. One such solution may be to produce the hydrogen onboard the vehicle at a rate that matches the rate of demand of the car engine. One method of on-board hydrogen production is to react a light metal with water. Boron is one of the most promising metal candidates for this purpose [2]. It is a light element with a molecular weight of $10.8 \mathrm{~g} / \mathrm{mol}$. The reaction of boron with water yields a high hydrogen-to-metal ratio compared to other metals (see Table 1) [3]. Moreover, boron is very safe to store and to transport because its ignition temperature is high in dry or moist air and even in water.

Table 1. Theoretical $\mathrm{H}_{2}$ produced by the hydrolysis of metals

\begin{tabular}{lcc}
\hline \multicolumn{1}{c}{ Reaction } & mole $\mathrm{H}_{2}$ /g-Fuel & STP L H $\mathrm{H}_{2}$ g-Fuel \\
\hline $2 \mathrm{~B}+3 \mathrm{H}_{2} \mathrm{O} \rightarrow 3 \mathrm{H}_{2}+\mathrm{B}_{2} \mathrm{O}_{3}$ & 0.139 & 3.00 \\
$2 \mathrm{Al}+3 \mathrm{H}_{2} \mathrm{O} \rightarrow 3 \mathrm{H}_{2}+\mathrm{Al}_{2} \mathrm{O}_{3}$ & 0.056 & 1.25 \\
$\mathrm{Mg}+\mathrm{H}_{2} \mathrm{O} \rightarrow \mathrm{H}_{2}+\mathrm{MgO}$ & 0.041 & 0.92 \\
$\mathrm{Fe}+\mathrm{H}_{2} \mathrm{O} \rightarrow \mathrm{H}_{2}+\mathrm{FeO}$ & 0.018 & 0.40 \\
$\mathrm{Zn}+\mathrm{H}_{2} \mathrm{O} \rightarrow \mathrm{H}_{2}+\mathrm{ZnO}$ & 0.015 & 0.34 \\
\hline
\end{tabular}

The ignition and combustion processes of boron have been of great interest to many researchers because of its high heating value. Considerable experimental [4-5] and theoretical research [4-9] has been conducted with the objective of understanding the ignition and combustion of boron particles in oxygen. The data show the ignition of boron particles is 
significantly delayed because of the formation of a layer of boron oxide $\left(\mathrm{B}_{2} \mathrm{O}_{3}\right)$ on the surface of the boron.

Several studies prove that adding water to the oxygen environment can increase the oxidation rate. This finding is of particular significance to the proposed study. It is suggested that the increased oxidation rate is due to gasification of the protective $\mathrm{B}_{2} \mathrm{O}_{3}$ layer to boric acid $\left(\mathrm{HBO}_{2}\right)$. Smolanoff et al. [10] showed that the addition of water to the boron/oxygen reaction yields a higher reaction rate than when $\mathrm{HF}(\mathrm{g}), \mathrm{CO}_{2}(\mathrm{~g})$, and $\mathrm{BF}_{3}(\mathrm{~g})$ are added. Data obtained by Krier et al. [11] show that the addition of water reduces the ignition delay time and reduces the ignition temperature for combustion of boron when compared to combustion in pure oxygen. Vovchuk et al. [12] measured $\mathrm{B}_{2} \mathrm{O}_{3}$ gasification rates in pure water and dry air atmospheres for temperatures as high as $1303 \mathrm{~K}$. They found that the gasification rates for $\mathrm{B}_{2} \mathrm{O}_{3}$ in water vapor were significantly greater than those in air. Sontgen et al. [13] found that the addition of 3 to $8 \%$ water vapor to air significantly increased the oxidation rate at 803 K.

Data on the hydrolysis of boron in the absence of oxygen are limited. Experiments in steam by Rosenband et al. [14] were the first to demonstrate that the production of hydrogen by this method is feasible. Vishnevetsky et al. [15] considered the hydrolysis of boron in the absence of oxygen at moderate reactor temperatures (below $873 \mathrm{~K}$ ). The hydrogen yield was 47 to $62 \%$ of the theoretical equilibrium value. It was confirmed that the reaction occurs only at temperatures above the melting point of boron oxide (723 K). Removal or thinning of the liquid oxide layer is attributed to a gasification reaction with steam that produces volatile metaboric acid. Limitations of the test apparatus excluded experiments above $873 \mathrm{~K}$, where the gasification rate of boron oxide increases and higher hydrogen production yields are expected.

The objective of this paper is to investigate the effect of temperature on boron hydrolysis (2B $\left.+3 \mathrm{H}_{2} \mathrm{O} \rightarrow 3 \mathrm{H}_{2}+\mathrm{B}_{2} \mathrm{O}_{3}\right)$ and to study the effect of boron oxide gasification reaction $\left(\mathrm{B}_{2} \mathrm{O}_{3}(\mathrm{l})\right.$ $\left.+3 \mathrm{H}_{2} \mathrm{O}(\mathrm{g}) \rightarrow 2 \mathrm{H}_{3} \mathrm{BO}_{3}(\mathrm{~g})\right)$ on the hydrolysis process.

\section{Methodology}

The experimental setup is shown in Figure 1. A $100 \mathrm{~cm}$ long and $2.3 \mathrm{~cm}$ i.d. tubular, quartz reactor is placed inside a tubular furnace $(40 \mathrm{~cm}$ long, concentric, cylindrical, electric ceramic heater). Steam was generated upstream in an electrical heater. The amount of steam generated was controlled by controlling the water flow via a peristaltic pump. Prior to each experiment, a crucible was loaded with weighed boron particles of 0.1 grams (amorphous, 97\% pure) and placed in the reactor. Each time, the reactor was closed, evacuated and purged with $\mathrm{N}_{2}$. The nitrogen flow rate was $0.3 \mathrm{l} / \mathrm{min}$ during the whole experiment. When the desired temperature $(873 \mathrm{~K}, 973 \mathrm{~K}, 1073 \mathrm{~K})$ in the furnace was reached, the steam flow was directed into the reactor $(0.54 \mathrm{~mL} / \mathrm{min}$, equivalent to $1 \mathrm{rpm}$ in the peristaltic pump). During the experiment, the excess of steam was condensed into a water vapor trap. The outlet gas was analyzed continuously using an inline gas chromatograph (Varain 430 GC). The GC was fixed in automatic sampling mode and started to record data as soon as the steam valve was opened. Each run lasted 2 minutes. 


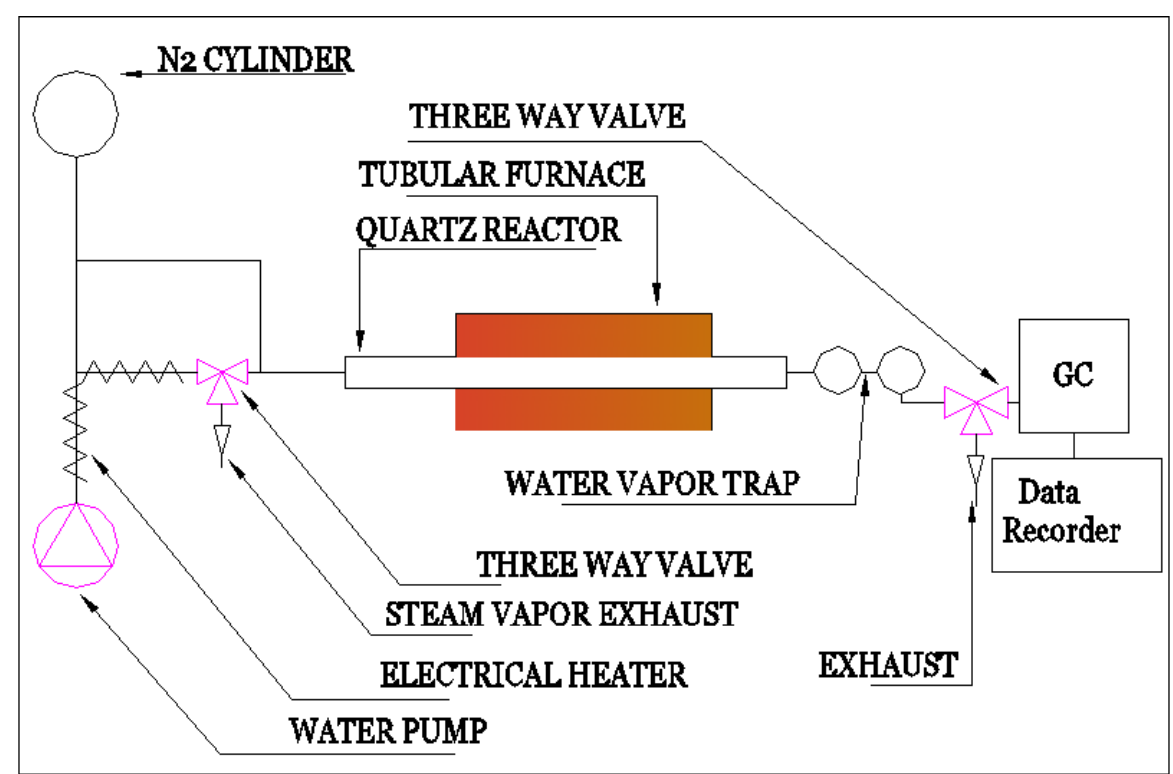

Fig. 1. Boron hydrolysis experimental setup

To examine the gasification of the oxide layer produced, small changes have been made to the experimental setup. A shorter quartz reactor $(60 \mathrm{~cm}$ length, $2.3 \mathrm{~cm}$ i.d.) was placed in the tube furnace. The outlet of the quartz tube was open. Prior to each experiment, 4 crucibles were inserted into the reactor with the same amount of boron powder $(0.1 \mathrm{~g})$ and placed in the reactor (dry and purged with $\mathrm{N}_{2}$ ). During the experiment, boron crucibles were pushed out from the reactor into $500 \mathrm{~mL}$ flasks that contain nitrogen gas in order to prevent any further oxidation with air. This process was conducted on a regular time interval: 3 minutes between each crucible. Then the mass of the crucible was recorded.

\section{Results and Discussion}

Figures 2a and $2 \mathrm{~b}$ show the hydrogen production at 973 and $1073 \mathrm{~K}$. The hydrogen production efficiency at $973 \mathrm{~K}$ was 86 and $98 \%$ for run 1 and 2, respectively. At $1073 \mathrm{~K}$, the efficiency was 93 and $90 \%$ for run 1 and 2 respectively. These values are much higher than the efficiency values obtained by Vishnevetsky at. al., [15]. In both of the runs at both of the temperatures, the hydrogen production followed the same trend. The hydrogen production reached the maximum at $\mathrm{t}=8$ and 10 minutes for 973 and $1073 \mathrm{~K}$, respectively.

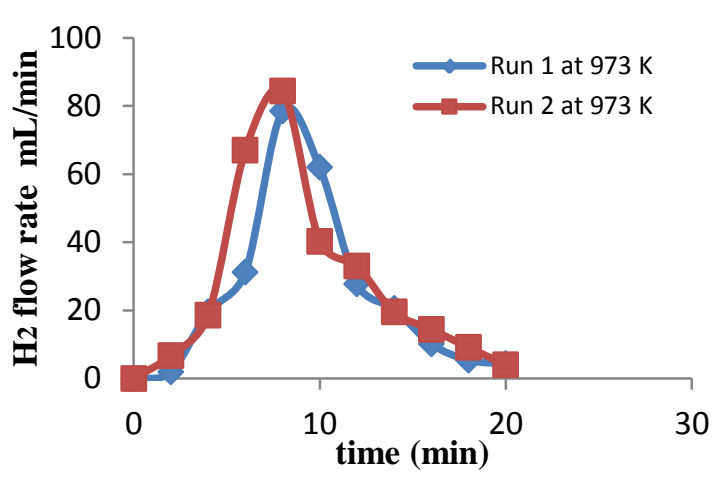

(a)

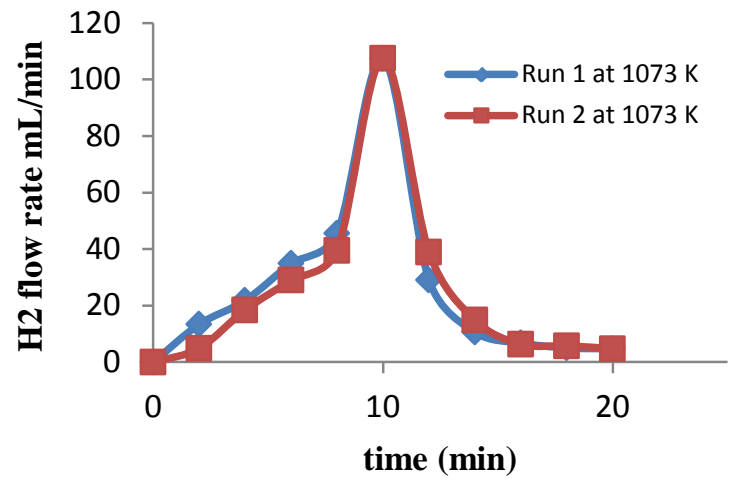

(b)

Fig. 2. Hydrogen production at a: $973 \mathrm{~K}$ and $b: 1073 \mathrm{~K}$

Figure 3 shows a comparison of the hydrogen production at 873, 973 and $1073 \mathrm{~K}$. As seen from this figure, at $873 \mathrm{~K}$, there was very low hydrogen production (efficiency only 5\%) for 
the period of the experiment. At 973 and $1073 \mathrm{~K}$, the first detected hydrogen production was after 2 minutes. At $1073 \mathrm{~K}$, the hydrogen production was higher than at 973K, but the efficiency was lower. Here, it is important to mention that the hydrogen analysis was performed every 2 minutes and that, most likely, there was more hydrogen produced than the values measured. The X-ray analysis shows that all the boron was converted to boron oxide and boric acid in the first 3 minutes.

In all runs, the hydrogen production started immediately after switching the steam valve on. This is confirmed by the visual observation of the condensation of boric acid and the gas chromatography analysis.

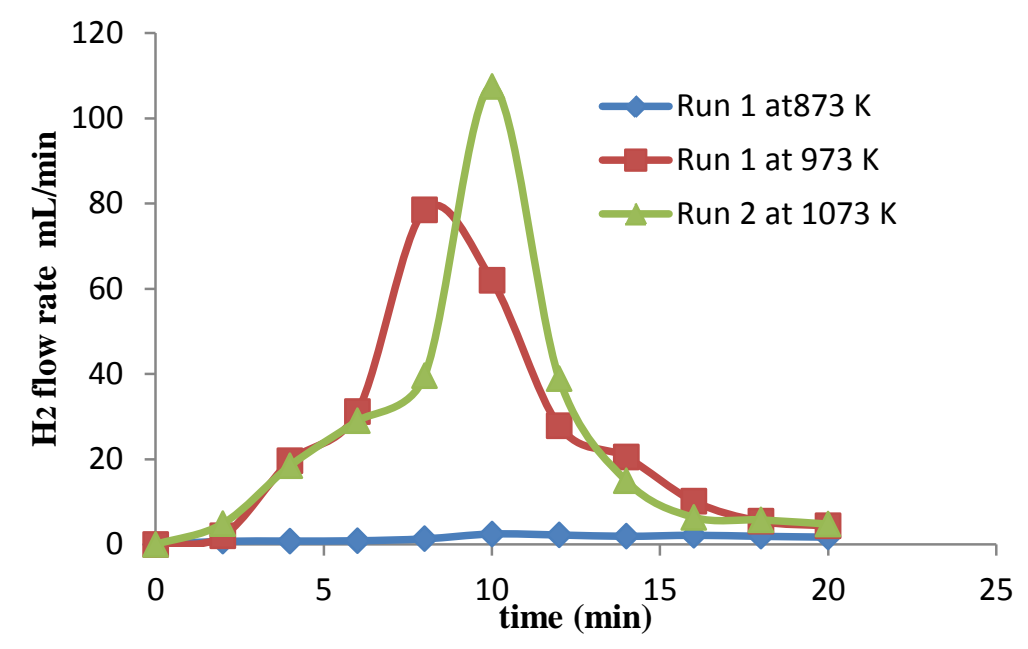

Fig. 3. $\mathrm{H}_{2}$ production comparison for different temperatures

From the first minutes of the reaction, a formation of white, glittery particles was observed on the inner wall of the quartz tube outside the furnace where the temperature is $376 \mathrm{~K}$. These particles start to condense on the tube directly after the steam valve is switched on (Figure 4a and $4 \mathrm{~b}$ ). These condensed particles continued to accumulate during the experiment and were very easy to remove. The X-ray analysis of these particles indicates that they are orthoboric acid (Figure 5). The formation of this layer is evidence of the gasification of boron oxide $\left(\mathrm{B}_{2} \mathrm{O}_{3}(\mathrm{l})+3 \mathrm{H}_{2} \mathrm{O}(\mathrm{g})=2 \mathrm{H}_{3} \mathrm{BO}_{3}(\mathrm{~g})\right)$ in parallel with the hydrolysis reaction.

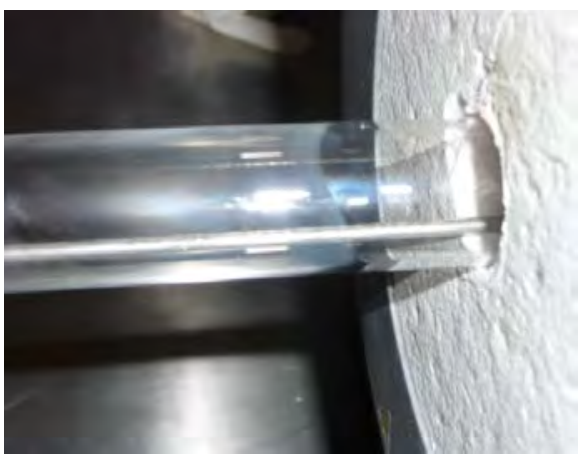

(a)

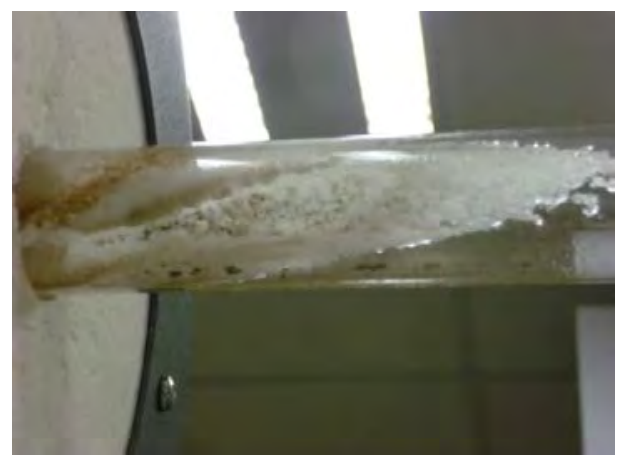

(b)

Fig 4. The condensation of boric acid on the inner wall of the reactor during the hydrolysis experiment. $a$ : at the beginning and $b$ : at the end of the experiment. 


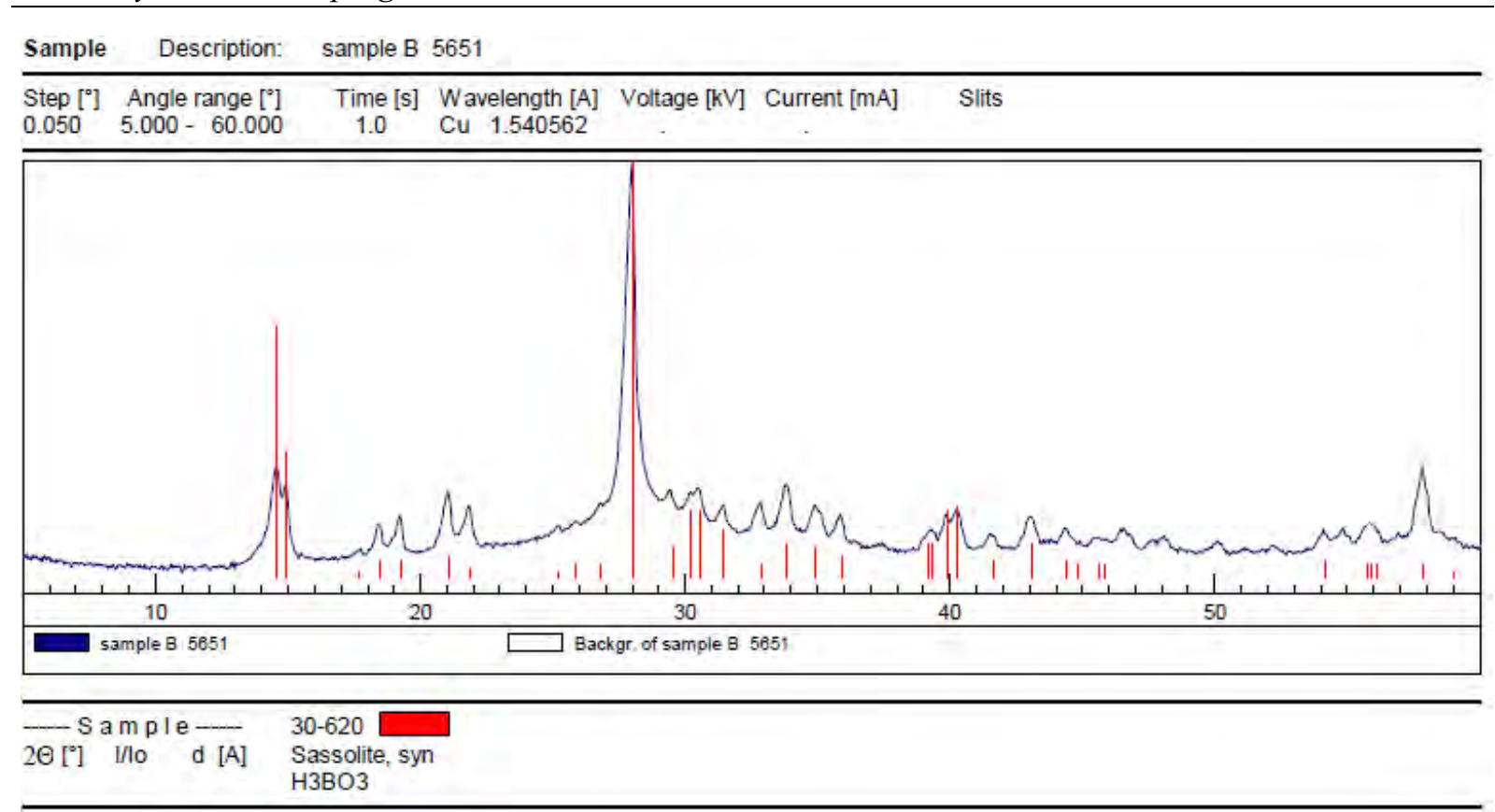

Fig 5. X-Ray analysis of condensed powder layer outside the furnace

Figure 6 shows the mass change during the hydrolysis of the boron powder at $973 \mathrm{~K}$. Theoretically the hydrolysis of 0.1 grams of boron will generate $0.638 \mathrm{~g}$ of boron oxide; but the maximum weight recorded during the experiment was $0.229 \mathrm{~g}$ after 6 minutes of the reaction. This is due to the immediate gasification of the boron oxide layer. This gasification process was observed during the hydrolysis experiments: a white color deposition of boric acid was observed at $\mathrm{t}=1 \mathrm{~min}$ of the hydrolysis experiment. After the sixth minute of the reaction, the weight of the particles in the crucible started to decrease. The X-ray analysis of the particles that remained in the crucibles shows 100\% boron oxide after 3 minutes (Figure 7).

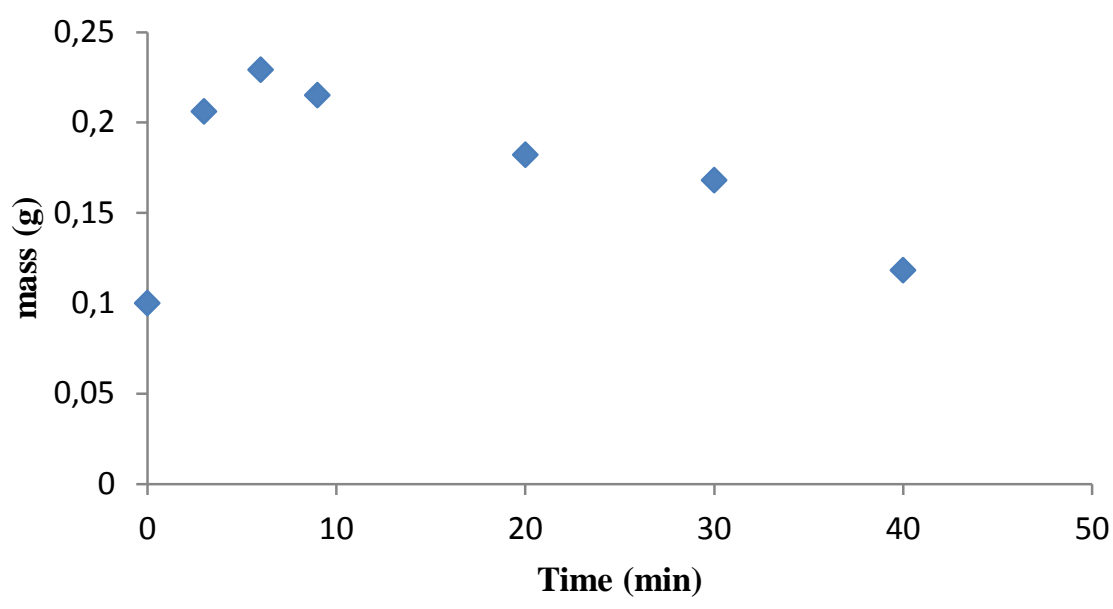

Fig. 6. Mass change in the boron sample during the hydrolysis process 


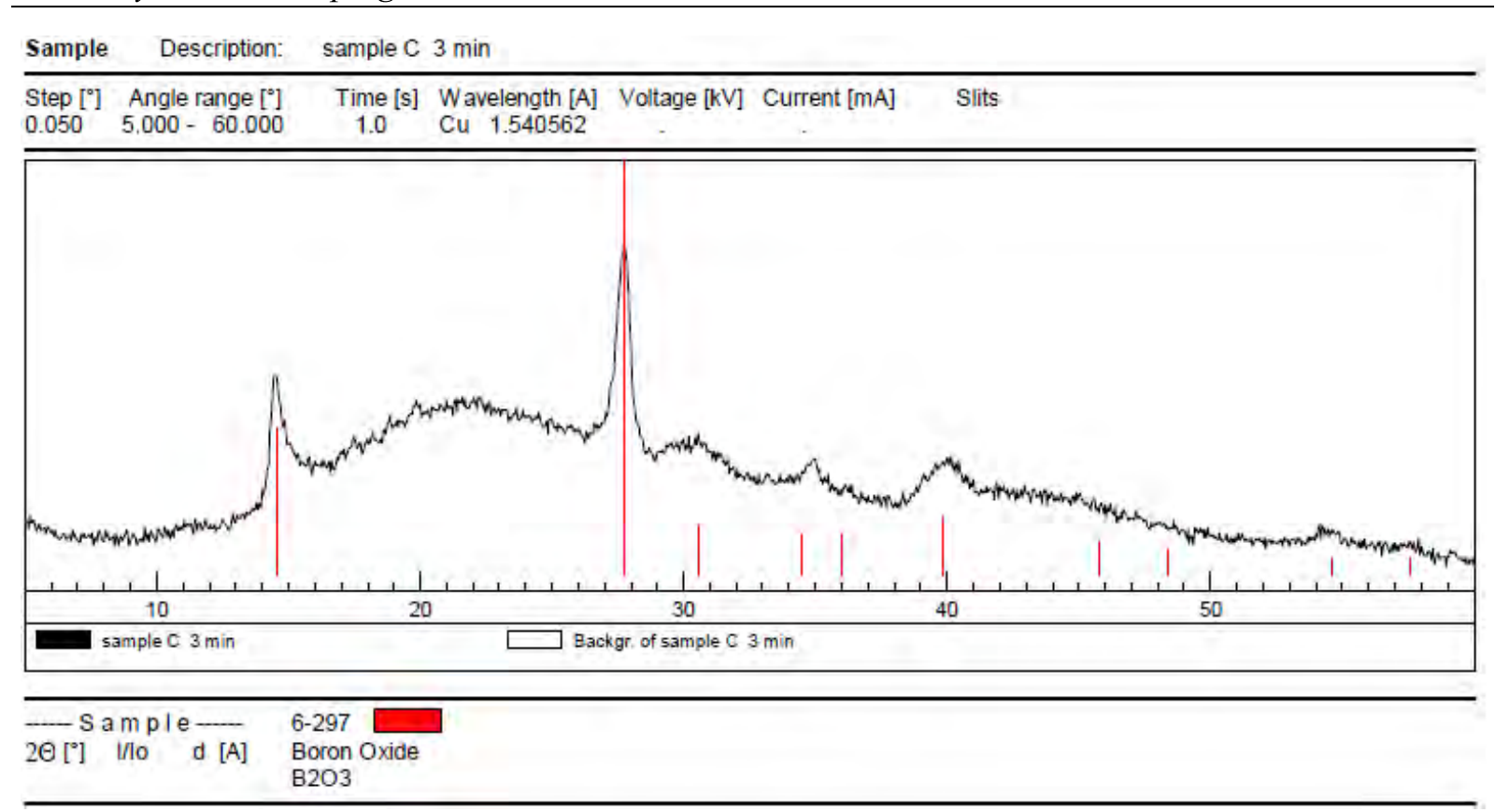

Fig 7. X-Ray analysis of particles remaining after the boron hydrolysis process ( $t=3 \mathrm{~min}$ )

\section{Conclusion}

In this study, a tubular reactor was built and operated for the hydrolysis of boron and the gasification of boron oxide in nitrogen carrier gas. Hydrogen production was measured at furnace set point temperatures of 873,973 and $1072 \mathrm{~K}$. The primary objective of these initial experiments was to understand the boron hydrolysis process.

Hydrogen conversion was $92 \%$ for both $973 \mathrm{~K}$ and $1073 \mathrm{~K}$. Very slow hydrogen production was observed at the temperature of 873K. Extensive deposition of boric acid was observed on the wall of the reactor outside the furnace where the temperature was $376 \mathrm{~K}$.

The hydrolysis experiments show parallel processes of boron hydrolysis and boron oxide gasification. X-ray analysis of the particles remaining in the crucible shows $100 \%$ boron oxide. Thus, we conclude that the boron hydrolysis reaction is faster than the boron oxide layer gasification. In other words, the chemical reaction between the boron and the steam is much faster than the chemical reaction between the boron oxide and the steam. The use of the boron/boron oxide thermochemical cycle for hydrogen production shows an advantage over other cycles, due to the ease of removal of the oxide layer. By comparison, in the zinc/zinc oxide $(\mathrm{ZnO})$ cycle, once a $\mathrm{ZnO}$ layer is formed, the hydrolysis reaction becomes limited by the diffusion of the reactants through the layer, which is harder to remove than the boron oxide layer [16].

\section{References}

[1] G. Karim, Hydrogen as a spark ignition engine fuel, International Journal of Hydrogen Energy 28, 2003, pp. 569-577.

[2] M. Epstein, Solar induced solid fuels for transportation, Proceedings of the $12^{\text {th }}$ International Symposium on Solar Power and Chemical Energy System, 2004, Oaxaca, Mexico, paper No. 302.

[3] T. Abu Hamed, J. Karni, M. Epstein, The use of boron for thermochemical storage and distribution of solar energy, Solar Energy 81, 2007, pp. 93-101. 
[4] C. L. Yeh, K. K. Kio, Ignition and combustion of boron particles, Progress in Energy and Combustion Science 22, 1996, pp. 511-541.

[5] C. C. Li, F. A. Williams, Ignition and combustion of boron particles in Combustion of boron-based solid propellants and solid fuels, Kuo, K. K., and Pein, R., Eds., Begell House Publishing Co. and CRC Press, Inc., 1993, pp. 248-271.

[6] S. C. Li, F. A. Williams, Ignition and combustion of boron in wet and dry atmospheres, Proceeding of the $23^{\text {rd }}$ Symposium on Combustion, 1990, pp. 1147-1154.

[7] M. K. King, Boron ignition and combustion in air-augmented rocket afterburners, Combustion Science and Technology, 1972, pp. 155-164.

[8] W. Zhou, R. A. Yetter, F. L. Dryer,H. Rabitz, R. C. Brown, C. E. Kolb. Comprehensive physical and numerical model of boron particle ignition. Proceeding of the $26^{\text {th }}$ International Symposium on Combustion, 1996 pp. 1909-1917.

[9] R. C. Brown, C. E. Kolb, S. Y. Cho, R. A. Yetter, H. Rabitz, F. L. Dryer, Kinetic model for hydrocarbon-assisted particulate boron combustion, International Journal of Chemical Kinetics 26, 1994, pp. 319-332.

[10] J. Smolanoff, M. Sowa-Resat, A. Lapicki, L. Hanley, S. Ruatta, P. Hintz, S. L. Anderson, Kinetic parameters for heterogeneous boron combustion reactions via the cluster beam approach, Combustion and Flame 105, 1996, pp. 68-79.

[11] H. Krier, R. L. Burton, S. R. Pirman, M. J. Spalding, Shock initiation of crystalline boron in oxygen and fluorine compounds. Proceeding of the $30^{\text {th }}$ American Institute of Aereonautics and Astronautics Thermophysics Conference, 1995, paper No. 2095-2120.

[12] Y. A. Vovchuk, A. N. Zolotko, L. A. Klyachko, D. I. Polishchuk, V. G. Shevchuk, Gasification of boron oxide, Fizika Goreniya i Vzryva 10, 1972, pp. 615-618.

[13] R. Sontgen, A. Freidrich, A simple model of the oxidation kinetics of boron in a medium containing water vapor, in Combustion of Boron Based Propellant and Solid Fuels, K. K. Kuo and R. Pein, Eds., Begell House Publishing Co. and CRC Press, Inc., 1993, pp. 211217.

[14] V. Rosenband, A. Gany, Y.M. Timnat, Magnesium and boron combustion in hot steam atmosphere, Defense Science Journal 48, 1998, pp. 309-315.

[15] I. Vishnevetsky, M. Epstein, T. Abu-Hamed, J. Karni, Boron hydrolysis at moderate temperatures - First step to solar fuel cycle for transportation, Journal of Solar Energy Engineering 130, 2008, pp. 14506-14511.

[16] R. J. Weiss, H. C. Ly, K. Wegner, S. E. Pratsinis, A. Steinfeld, $\mathrm{H}_{2}$ production by Zn hydrolysis in a hot-wall aerosol reactor, AIChE Journal 51, 2005, pp. 1966-1970. 